\title{
An Automated Model to Observer Attendance, Performance and Retention of theFirst Year Qatar University Students
}

\author{
Mohammad Shahid Jamil ${ }^{1}$, Khalid A. Ali ${ }^{2}$, Mohamed Chabi ${ }^{3}$ \\ Research and Planning Coordinator, Dept. of Math and Computer, Qatar University, Doha, QATAR ${ }^{1}$ \\ Associate VP, Qatar University, Doha, QATAR. ${ }^{2}$ \\ Lecturer and Academic Coordinator, Dept. of Math, Qatar University, Doha, QATAR ${ }^{3}$
}

\begin{abstract}
This article focuses on attendance, performance and retention of first year students of Math and Computer Department at the Foundation Program, Qatar University. A strategy has been developed to monitor attendance, performance and retention the students. To capture and analyse the data, a Monitoring system has developed and reported in this paper. Whenever student shows signs of absence with the poor performance then the Monitoring System start showing consequences with the aim of providing support for student at risk of failure or withdrawal at the early stage. Therefore, an intervention strategy assists to improve in attendance and performance with the dialogue among faculty, admin staff and students who are experiencing difficulties. The students physical attendance are most important factor to understand the learning material, to improve critical thinking and to elucidate problem solving based questions which leads to academic achievements in the research, learning system and to develop a knowledge base society. Data of each student is entered by the teacher in the Monitoring System from the day one of their classes.

This Monitoring system is developed using Oracle and Java to cater both presence of students and their achievements. Many faculties from Math and Computer department of Qatar University provided feedback to develop the system and still reinforce the on-going improvement. The developed Monitoring system is highly user friendly and easy to access within the university intranet. There are several reports that can be generating from the academic coordinator, HOD and system manager which give invaluable information about the students' and teachers' commitments. The attendance data can only be entered in the campus through intranet during the class hours which reduces the chance of errors, manipulations and biasness. If the teacher is unable to enter data then he/she has to explain the reasons for delay in entering data. Student can also monitor their earlier attendance percentage and outcome of the each result and can discuss if any discrepancy. This paper is very interesting to other tutors who want to use electronic attendance, control performance in each step and follow up students at risk. The research found that attendance are highly correlated with the student overall academic performance and retention of the student.
\end{abstract}

Keywords: Student Outcome. Student attendance, Intervention, Web-based System.

\section{INTRODUCTION}

Attendance is one of the factors used in measuring student engagement or participation in the educational process in schools and colleges. Educational institutions are probably spending a lot of time, utilizing resources and undertaking a great number of initiatives to combat truancy and other forms of non-attendance (Adelman \& United States. Office of Educational Research and Improvement. 1999; Reid, 2008). It is largely assumed that non-attendance leads in one way or another to lowering attainment. Chronic absenteeism can result in negative consequences for students and colleges. Student with more absentee have fewer opportunities to learn the material that affect the later higher course. Research on truancy and absenteeism suggests that students with better attendance score higher on achievement tests than their more frequently absent peers (Lamdin, 1996). DeKalb (1999) notes that student achievement is affected in a negative way by absenteeism. It is not claimed that attendance alone affects student achievement. There are many other factors that play a role in this, both in a direct and indirect manner. However, physical attendance is one of the most crucial and important parameter in an educational institution.

Copyright to IJARCCE
This study sheds light on this aspect such that educators can gain knowledge and insight regarding the relationship if any - between students class attendance and their achievement.

There have been relatively few controlled studies on the association between attendance and academic performance (Moore, 2004). Most of the studies focus on a single module. It would be an oversimplification to assume that all disciplines within higher education experience the same issues in the same way.

Colby (2004) has found a strong correlation between attendance and student performance. He put it very clearly that "There is a very clear correlation between attendance and attainment". He collected attendance data for 178 students on a first-year module, Internet Application Development, within the School of Computing at the University of Central England, Birmingham. A signature and honesty method was used to record student attendance during each teaching session. A strong, positive relationship between student attendance and success was observed.

www.ijarcce.com

8636 
(Roby, 2003) in a study on Ohio students found a very significant correlation between attendance and achievement. The correlation coefficient in his study ranged between 0.55 to 0.78 .

Hammen (1994), however reported a weak relationship between student attendance and attainment in a human physiology course, and stated that absence has only minor effects upon assessment performance. According to them, examination questions need not depend on lecture material; rather, revising the literature on a particular subject in textbooks may be sufficient.

\section{WHY INSTITUTIONS MONITOR ATTENDANCE?}

Student attendance has for a long time been an area of concern to academic institutions. It has been linked to their attainments. Student non-attendance can be an indicator of many problems, both individual to the learner and to the university at large. To support students and address institution-specific problems, attendance data should be researched and results feedback into the planning process; this information can then be used to create and maintain effective planning and support systems to help learners succeed (Bowen, Price, Lloyd, \& Thomas, 2005; Reid, 2008).

But in many higher education institutions it seems that 'policy on attendance is often non-existent and where it is considered, it certainly seems to vary not only from university to university but even from department to department (Cohn \& Johnson, 2006).

\section{A. Main Reasons for absentees}

Data has been collected and analysed to determine the fundamental reasons for non-attendance. According to Reid(2008), "causes for non-attendance can be categorized into these nine factors:

\section{Parents and guardians:}

Parental-control absenteeism, parents failing to accept their legal responsibilities. Mostly in the family they have lots of parties and other works. They overlook the importance of present in the class.

\section{Society:}

Insufficiently valuing education. Typically society is disagreeing with the quality education and they want to be good business man rather than scientist.

\section{Schools:}

Poor teaching, quality and standard in most of the school is very week especially in Science and English.

Inconsistent approach to absenteeism between and within schools and they do not act of absentees rule.

\section{Government:}

Lenient application of law, In Qatar the Government is very good and strong in all the mater but week in the development of the educational environment, Unsuitable curriculum for some pupils. Few out-of-school/alternative curriculum places

\section{Students:}

Copyright to IJARCCE
Bullying, peer pressure, 'cool' to skip school. Most of them they do not care but now some people started forcing their kid for quality.

Lack of career aspirations.

Low self-esteem.

\section{Education jurisdictions:}

Inconsistent policies and practices of local schools and education welfare services.

Inconsistent referral policies between schools.

Confused role of social services in non-attendance cases.

\section{Local economy:}

Local unemployment, poverty, poor community facilities. In Qatar most of the local they have good quality of jobs depending upon the qualification so unemployment rate is low.

\section{Cultural diversity:}

Differences between boys' and girls' aspirations and achievements. Most of the people in the gulf they like girls baby.

Rise of disaffected youth antisocial behaviour

Absence can be viewed as a very personal decision based on both the ability to attend and the motivation to attend (Kottasz, 2005). There seems to be some concern moreover that non-attendance is an indicator of lack of motivation amongst students.

Fleming asserts in the article "Why don't they attend? that "The major reasons given by students for non-attendance at learning events are assessment pressures, poor lecturing, inconvenient timing of the lecture and poor quality of lecture content" as cited in (Newman- Ford, Fitzgibbon, Lloyd, \& Thomas, 2008).

(Johnson, 2003), however, classifies attendance monitoring into two main forms, namely local and global monitoring. In the local level attendance is analysed soon after learning events to identify students who may be silently withdrawing and in that case it signals that these students could be at-risk especially if attendance data is linked to attainment data in institutions that follow the continuous assessment methods. Early identification of silent withdrawals enables the institution to take a proactive approach in retention, assisting students before the situation becomes irretrievable (Bowen et al., 2005).

Global monitoring is the analysis of historical attendance data, where different groups, modules, department rather than individual students with the aim of identifying group trends and patterns, strategies to enhance student success, such as changes in the curriculum and better targeted resources, can be developed.

However, benefits of local and global attendance monitoring are dependent upon the quantity and quality of information, as inaccurate or incomplete attendance information could mislead. Therefore attendance data must be complete, up to date, accurate and useable.

Chronic absenteeism can result in other negative consequences for students and institutions. Students who are not attending a learning event have less chance to learn the material that enables them to succeed later in college. Research on absenteeism suggests that students who have www.ijarcce.com 
good attendance record score higher grades onv. achievement tests than those with poor records. According to Kottasz (2005) "Two-fifths of students in the UK claim that their university education is suffering because they have to work part-time." Longhurst share the same note in his article why aren't they here? Student absenteeism in a further education college that "a high proportion of students fail to attend due to work commitments" (Newman- Ford et al., 2008). These causes are hardly applicable to the students in Qatar University at undergraduate level

\section{B. Other Factors for absence of QU Students}

In addition to the factors above listed, students in QU have different causes for absent. These are socio-economic factors and cultural of the society factors. These are some of these factors include:

i. Transportation: Public transports to the University are almost non-existent, so the majority of students use private transportation and if there is breakdown to the car they usually don't show.

ii. Social issue: Most of the local do not allow their female kids to use public transport/taxis to reach university

iii. Class Timing: Male student does not like morning class time because they play in the night time so to reach in the morning is difficult and they skip classes whenever they feel tired. Similarly female student does not like evening classes because of the family restrictions to go out in the evening.

iv. Family Problem: If any small issue happen within the family then the female student skip their classes easily.

v. Unnecessary discussion: Some time the student just start talking about some issue and they gets fully involve and then they missed their class.

vi. Do not like Faculty: Some student does not like some faculty and their style of teaching. They feel boring and hence they remain absent from the classes of that faculty/instructor.

vii. Need to complete other assignment: Some student wants to complete other assignment with the help of class friend so they miss the class and complete their work during the lecture time.

\section{Importance of attending class}

i. Tutors provide reading and practicing assignments with their precise presentations.

ii. Discussions and elaborations with teachers and other classmates can be on latest scenario which may not be found in books and this discussion can be more beneficial and clear many other doubts also. Sometime teachers advance the level of discussion to enhance critical thinking skills and relate with real life examples.

iii. Enhance students' interaction with faculty leads an ability of the leadership quality and personality development.

iv. Student learn what they need to know and don't need to know and then sometime they find interesting,
Proper skill and problem solving capability cannot if large numbers of students are frequently absent in class. The student skill will below the mark with the student who are regular in the class and ultimately reflect in the outcome of the student.

\section{Types of attendance taking}

Educational institutions take attendance by two main methods:

a. Manual:

i. Calling name or roll number: When a teacher call student's name one by one to confirm the presence but there is chance of proxy or duplicate representation.

ii. Signature system: Teacher rotates paper to all students to sign in front of their name. But teacher don't have any system to testify the student signature so any one can sign for other or $\mathrm{S} / \mathrm{He}$ can sign in duplicate but at the end teacher can count to justify the number of present student.

\section{b. Automatic:}

i. When student enter in the lab class and when they login in the computer with their username and password then presence is recorded.

ii. Asked student to scan their figure on biometric device to record their presence.

iii. While entering in the class each student retina may be scanned to record their presence.

\section{c. Hybrid:}

Where attendance is entered manually to the computerized developed system. This system can provide different report to analyze.

\section{E. QU Attendance and Bonus Strategy}

According to Qatar University policies: “attendance is a very important factor in student performance and will be taken from the first day of classes". A strict procedure is followed regarding attendance. To encourage student presence in the class Foundation Program, QU adopted bonus strategy to be granted based on the presence in the class.

If a student is absent for two lectures (10\%) then he/she gets a first warning. If a student is absent for four lectures $(20 \%)$ then a final warning is sent to the student.

A student with five lectures absence is considered FB (Fail Barred) where he/she:

Such a students' Final exam will not be examined and absent will be recorded.

But allowed to attend the remaining sessions as a listener without assigning any grade.

To inspire presence in class in lower class and improve motivation for students the QU Foundation Program has devised an incentive system that students can benefit from by giving extra bonus marks (1-3) according to their attendance base on the department policy. Many students benefited from this bonus system, but it was noted that in most of the cases only good students improved their final grade benefiting from bonus marks. But if a student receives full marks in all the exams then instead of 103 marks only 100 will be assigning to their final grade. 


\section{III.Monitoring SYSTEM at Foundation Program}

The system used in QU is a hybrid system. Teacher call the names from the list of Monitoring developed software at the beginning of the lecture and enter present $(\mathrm{P})$ or absent(A) in the web-based system. Here a teacher just intervenes to enter status in the Monitoring system. This attendance sheet can be modified during the class time. Once the time is over then even a teacher cannot change without the permission of the academic coordinator.

The system then calculates all the status of the student if a student deserves first warning, final warning or barring, and sends the notices when directed by the teacher. In addition to these notices the system delivers many reports such as: lists of first warning, final warning, barred students for each course and group of students. Figure 1 shows list of student received warning. The orange highlighted is warned student and pink highlighted shows the barred student.

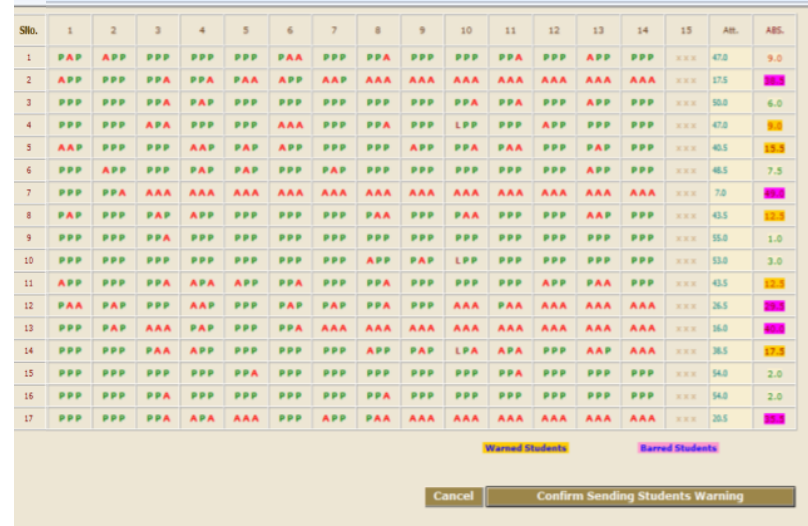

Figure 1 Student Attendance/Sending Warning

The statistics and reports produced by the system are very useful to control the student presence. Whenever a tutor issues warning notice then it will be recorded with date

\begin{tabular}{|c|c|c|c|c|c|c|c|}
\hline stha & $\begin{array}{l}\text { Actual } \\
\text { Ant }\end{array}$ & Finst Warning & Date Finst Warning & Secoos Warning & Dote Second Warning & Fal barred & Barned ote \\
\hline 1 & 48.5 & ont & null & ont & noll & nult & nul \\
\hline . & 17.5 & 10.5 & 14-11-2013 & 14.5 & 21-11-2013 & 19 & 03-12-2013 \\
\hline 3 & 55.0 & not & null & mull & null & not & noll \\
\hline 4 & 53.0 & not & null & ond & mull & null & null \\
\hline 5 & 50.0 & nat & nult & nult & nod & mall & nol \\
\hline 6 & 7.0 & 9 & $24-10-2013$ & 21 & 14-11-2013 & 25 & 21-11-2013 \\
\hline 7 & 16.0 & 12 & 14-11-2013 & 16 & 21-11-2013 & 20.5 & 03-12-2013 \\
\hline 3 & 54.0 & noll & oul & oult & null & nut & nult \\
\hline 9 & 43.5 & 8.5 & 21-11-2013 & nult & nut & null & oul \\
\hline 10 & 47.0 & null & oult & null & null & null & noll \\
\hline 11 & 26.5 & 10 & 14-11-2013 & 15 & 05-12-2013 & 17.5 & 12-12-2013 \\
\hline 12 & 47.0 & 9 & 17-12-2013 & nat & noll & nat & nud \\
\hline 13 & 54.0 & nout & not & noll & null & nut & noll \\
\hline 14 & 20.5 & 9 & 14-11-2013 & 16 & 03-12-2013 & 18.5 & 05-12-2013 \\
\hline 15 & 43.5 & 9.5 & 05-12-2013 & null & null & nut & null \\
\hline 16 & 38.5 & 10.5 & 12-12-2013 & oull & noll & nat & noll \\
\hline 17 & 40.5 & 9 & 14-11-2013 & sull & null & null & null \\
\hline
\end{tabular}

Figure 2 Student first, second and barred list with date. and barring list will be automatically prepared. In this figure 2 gives the first warning, second warning and barred list with date. The figure 3 shows the grade book for each student within the class. The teacher can follow with student to discuss performance. Whenever the performance is low in any step then teacher can contact that student and do the needful to improve performance. The student can also access his/her attendance and performance record and can contact his teacher any time. 
This Monitoring is complete system to track attendance and performance. The proper action can be taken based on the need of the student.

\section{IV.RESEARCH STRATEGY}

Study has been conducted in the Math and Computer Department courses of Foundation Program, QU. Student attendance and its relationship to student attainment in QU doing Mathematics and Computer courses will be reviewed using the following research finding:

i. Is there a significant, positive relationship between student attendance and student performance?

ii. Does this correlation exit for both Math result with attendance and Computer result with attendance?

iii. Is there a statistically significant similarity with the result of the same student of both the department?

iv. What strategy should adopt to improve the result in may be passing or fail category of student?

v. Is retention/drop rate of student at risk effect after adopting our strategy?

\section{A. Methodology and Finding Strategy:}

Data of students collected were analysed. Statistical analysis was carried out to find out if any correlation exists between attendance percentage and performance of the both the department similar student. The collected for those students who took Math course and Computer course. Some student either exempted Math course after achieving result in ACCUPLACER-MATH or ACT MATH or exempted Computer course after achieving appropriated result in IC3. These students are excluded in this study. The students who are present in both the course are analysed. Data collected every week based on the event. Then result after 9 weeks are shown in the table1. Here passing percentage is 70 .

Collected Data has been categories in the three fold.

i. Number of student who secured more than 70 means they are sure pass and can clear course.

ii. Number of student who secured less than 40 means they are sure fail even if they secure full marks in the remaining exam.

iii. Number of student who secured between 40 and 70 mean they may be pass or fail. If they work properly then they will pass the course otherwise they will fail in this. Assumption made that everyone will work hard to clear course. These types of students are important for our analysis.

The percentage calculated for Sure Pass, Sure Fail and May be Pass or Fail with their overall attendance performance for 793 students from four different major. Following result of math department has found that Sure Pass student passing percentage is $70.74 \%$ and their overall average attendance if $87.60 \%$. Whereas Sure Fail student failing percentage is $9.21 \%$ and their overall attendance is $43.74 \%$. Then May be Pass or Fail students are $20.05 \%$ with overall attendance $69.32 \%$. Which clearly show that the student who is attending classes and following our strategy during the course are doing better than who is not attending class regularly.

\begin{tabular}{|c|c|c|c|c|c|c|}
\hline \multicolumn{7}{|c|}{ Math Overall Result Performance with Attendance in Major wise (Till 9 weeks) } \\
\hline Major & $\begin{array}{c}\text { Total } \\
\text { Student }\end{array}$ & \begin{tabular}{|c|} 
Number of \\
student whose \\
Total Marks >= \\
70 \\
\end{tabular} & $\begin{array}{l}\text { Attendance } \\
\text { Average }\end{array}$ & $\begin{array}{c}\text { Number of student } \\
\text { whose Total Marks } \\
\qquad<=40\end{array}$ & $\begin{array}{l}\text { Attendance } \\
\text { Average }\end{array}$ & $\begin{array}{c}\text { Marks } \\
\text { Between } 70 \\
\text { and } 40\end{array}$ \\
\hline $\begin{array}{l}\text { Artand } \\
\text { Science }\end{array}$ & 411 & 294 & $80.52 \%$ & 52 & $57.47 \%$ & 65 \\
\hline Education & 25 & 15 & $85.03 \%$ & 2 & $64.00 \%$ & 8 \\
\hline Engineering & 348 & 248 & $89.81 \%$ & 18 & $53.51 \%$ & 82 \\
\hline Pharmacy & 9 & 4 & $95.12 \%$ & 1 & $0.00 \%$ & 4 \\
\hline Total & 793 & 561 & & 73 & & 159.00 \\
\hline \multicolumn{5}{|c|}{ Pass or Fail Percentage } & \multicolumn{2}{|c|}{ Overall Average Attendance } \\
\hline \multicolumn{4}{|c|}{ Sure Pass = } & $70.74 \%$ & \multicolumn{2}{|c|}{$87.60 \%$} \\
\hline \multicolumn{4}{|c|}{ Sure Fail = } & $9.21 \%$ & \multicolumn{2}{|c|}{$43.74 \%$} \\
\hline \multicolumn{4}{|c|}{ May be Pass or Fail= } & $20.05 \%$ & \multicolumn{2}{|c|}{$69.32 \%$} \\
\hline
\end{tabular}

Main challenge here is the student between 40 to 70 marks because still 5 weeks of teaching available.

Similar data collect has been collected for the Computer Department common 793 students from four different major shows in table 2 .

\begin{tabular}{|c|c|c|c|c|c|c|}
\hline \multicolumn{7}{|c|}{ Computer Overall Result Performance with Attendance in Major wise (Till 9 weeks) } \\
\hline Major & $\begin{array}{c}\text { Total } \\
\text { Student }\end{array}$ & $\begin{array}{l}\text { Number of } \\
\text { student } \\
\text { whose Total } \\
\text { Marks }>=70\end{array}$ & $\begin{array}{c}\text { Attendan } \\
\text { ce } \\
\text { Average }\end{array}$ & $\begin{array}{c}\text { Number of } \\
\text { student } \\
\text { whose } \\
\text { Total } \\
\text { Marks < } \\
40\end{array}$ & $\begin{array}{l}\text { Attendance } \\
\text { Average }\end{array}$ & $\begin{array}{c}\text { Marks } \\
\text { Between } 70 \\
\text { and } 40\end{array}$ \\
\hline Art and Science & 411 & 329 & $82.92 \%$ & 30 & $67.47 \%$ & 52 \\
\hline Education & 25 & 18 & $83.34 \%$ & 4 & $54.00 \%$ & 3 \\
\hline Engineering & 348 & 294 & $90.45 \%$ & 12 & $60.51 \%$ & 42 \\
\hline Pharmacy & 9 & 7 & $96.81 \%$ & 1 & $0.00 \%$ & 1 \\
\hline Total & 793 & 648 & & 47 & & 98.00 \\
\hline \multicolumn{5}{|c|}{ Pass or Fail Percentage } & \multicolumn{2}{|c|}{ Overall Average Attendance } \\
\hline \multicolumn{3}{|c|}{ Sure Pass percentage $=$} & \multicolumn{2}{|r|}{$81.72 \%$} & \multicolumn{2}{|r|}{$88.40 \%$} \\
\hline \multicolumn{3}{|c|}{ Sure Fail Percentage= } & \multicolumn{2}{|r|}{$5.93 \%$} & \multicolumn{2}{|r|}{$45.49 \%$} \\
\hline \multicolumn{3}{|c|}{ May be Pass or Fail } & \multicolumn{2}{|r|}{$12.36 \%$} & \multicolumn{2}{|r|}{$78.30 \%$} \\
\hline
\end{tabular}

Following result of Computer department has found that Sure Pass student passing percentage is $81.72 \%$ and their overall average attendance if $88.40 \%$. Whereas Sure Fail student failing percentage is $5.93 \%$ and their overall attendance is $45.49 \%$. Then May be Pass or Fail students are $12.36 \%$ with overall attendance $78.30 \%$. Here also the same fact has been found that the student who is attending classes regularly are doing better than who is not attending class. Here also nearly same strategy adopted to assist weak student or student of special need. Finally correlation between the department result and attendance has been analysed as show in table 3.

\begin{tabular}{|l|l|c|}
\hline \multicolumn{3}{|c|}{ Correlation } \\
\hline \multicolumn{2}{|c|}{ Result } & Attendance \\
\hline Sure Pass & 0.999147 & 0.96473391 \\
\hline Sure Fail & 0.996838 & 0.957570271 \\
\hline May be Pass or Fail & 0.945381 & 0.96243432 \\
\hline
\end{tabular}

Table 3 Correlation between Both departments in Result and Attendance First correlation calculated with all student of different major of Sure pass with Math and Computer Department shows strong correlation and similarly strong correlation between the attendance of Math and Computer student 
May be Pass or Fail student. Therefore, same student are doing better if they are attending classes regularly. Data again analysed after all exam shown in table 4 and found only $4.4 \%$ student fail from student at risk level. Those students' marks were between 40 to 70 ranges worked on the planned strategy and performed better in this class.

B. Strategy adopted to improve the performance and retention of these students.

i. Motivation discussion with class teacher, each teacher sits some extra time with their students to motivate and provide them value and usefulness of the course they are studying. Sometime teacher gives some daily life problem and try to solve with help of courses are covering.

ii. Discussion with Admin staff, student can discuss with admin to share their problem(s) in the course, teacher, environment and sometime personal issue about transport, class time, free time, their kids etc.

iii. Workshop in labs/classrooms, department provide extra time to the weak students to improve their skill and encourage them to understand and to practice further.

iv. Extra tutorial, department collects the information of the student at risk and arrange extra contact hours with the same teacher or with the different teacher.

v. Running similar course, department prepares list all difficult topics and schedule them to cover by different teacher in off time so that student can see topics and come to attend whenever they require or whenever they face difficulty in the class on that topic.

vi. Complain Form, On top of the study plan department provide complain box where a student can write their any concern and then it is the duty of admin staff to resolve these issue within one week.

vii. Extra office hours, whenever the teacher feel that they class are unable provide better than average gave then he collect these type of student and arrange some extra office hours to improve skills.

viii. Extract marks of each objective, teacher prepare the table of all their students marks in each objective and locate the student having weak performance in particular objective so that objective/lesson can be reorganize and further cover in extra class to improve results.

ix. Provide video, Lessons of most of difficult topics/objectives are prepare in the form of video or animation using Captivate Software uploaded in blackboard so that student can run repeatedly this video to understand in any free time from any location. Teacher also sees the number of hits and duration used to cover these objectives.

$\mathrm{x}$. All the above arrangement is recoded to analyse the result further.

\section{Performance Analysis:}

After implementing the above strategy the fact has been evolved that result of students improved and the department has managed to retain most of the student at risk.

\begin{tabular}{|c|c|c|c|c|c|c|c|c|}
\hline \multicolumn{9}{|c|}{ Computer and Math Final Performance in each Major } \\
\hline Major & $\begin{array}{l}\text { Total } \\
\text { Student }\end{array}$ & $\begin{array}{c}\text { Overall } \\
\text { Pass } \\
\text { Student }\end{array}$ & $\begin{array}{c}\text { Overall } \\
\text { Fail } \\
\text { Student }\end{array}$ & $\begin{array}{l}\text { Overall } \\
\% \text { of } \\
\text { Fail } \\
\end{array}$ & $\begin{array}{c}\text { Student } \\
\text { Between } 70 \\
\text { and } 40 \text { Marks }\end{array}$ & $\begin{array}{c}\text { Completed } \\
\text { Course }\end{array}$ & $\begin{array}{c}\text { Fail } \\
\text { Student }\end{array}$ & $\begin{array}{l}\text { \% of Fail } \\
\text { (Student } \\
\text { between } 40 \& \\
70 \text { \& } \\
\end{array}$ \\
\hline $\begin{array}{l}\text { Art and } \\
\text { Science }\end{array}$ & 411 & 355 & 58 & $14.11 \%$ & 65 & 59 & 4 & $6.15 \%$ \\
\hline Education & 25 & 22 & 3 & $12.00 \%$ & 8 & 7 & 1 & $12.50 \%$ \\
\hline Engineering & 348 & 328 & 21 & $6.03 \%$ & 82 & 79 & 2 & $2.44 \%$ \\
\hline Pharmacy & 9 & 8 & 1 & $11.11 \%$ & 4 & 4 & 0 & $0.00 \%$ \\
\hline Total & 793 & 713 & 83 & $10.47 \%$ & 159 & 149 & 7 & $4.40 \%$ \\
\hline
\end{tabular}

Student at risk from engineering major failed only $2.44 \%$ and overall fail student was $4.40 \%$. This shows an improvement. The chart has been driver from the above data.

\section{Overall Student Result}

- Total Student Overall Pass Student Overall Fail Student

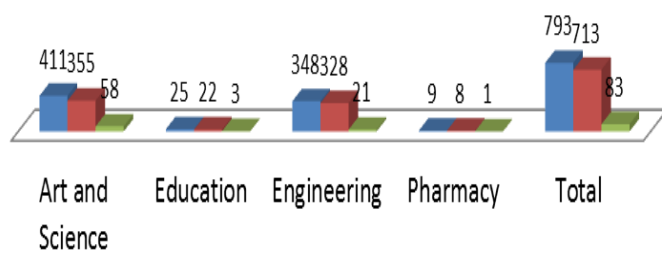

Chart 1 Overall Pass or Fail

Student between 40 and 70 performace

- Student Between 70 and 40 Marks Completed Course Fail Student

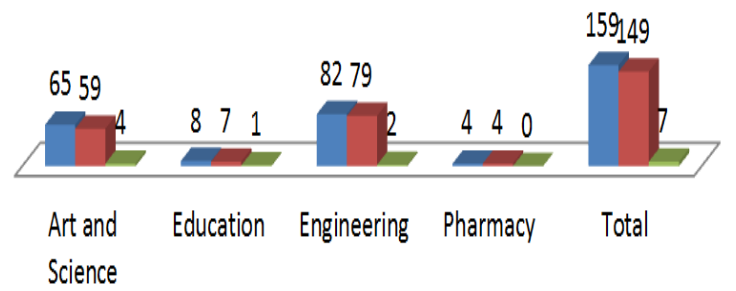

Chart 2 Performance in each department having marks between 40 to 70

Other fact has been driven that percentage of attendance and their grade performance. The chart below is for attendance rates and final grades of students for both department and found the fact that less average attendance secure lower grade.

The chart proves beyond any doubt that there is a strong relationship between attendance and academic achievement. Moreover it shows no significant difference as regards subject area Math and Computer course. 


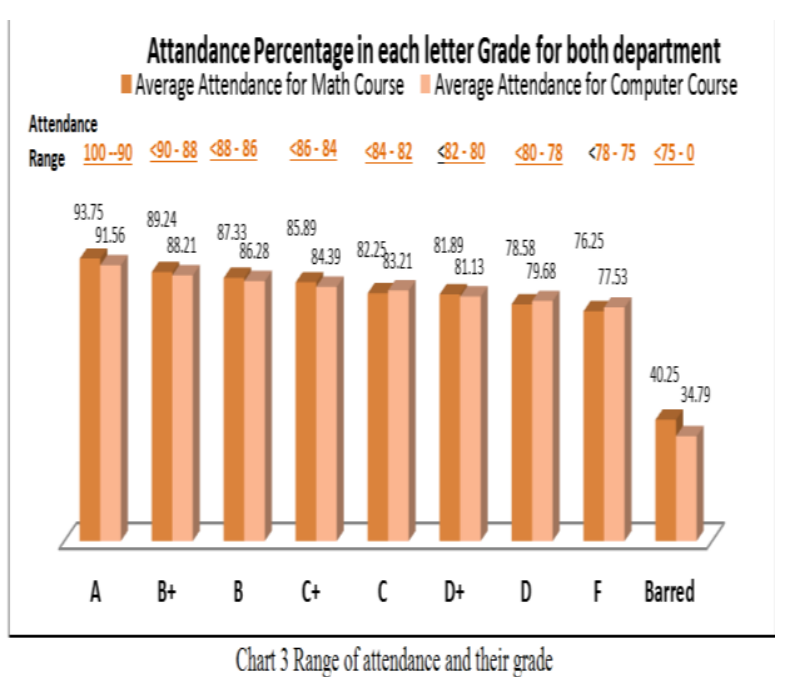

\section{Retention/Drop analysis:}

Retention rate data collected to analyse and it is found that after implementation of our strategy the retention is more specially for those student at-risk whose has marks between 40 to 70 . In fall2012 andspring 2013the drop rate was very less only $2.98 \%$ and $3.28 \%$ student dropped or change their major which much better and 4 to 5 times less than the earlier semester. The student was more enthusiastic and motivated after our new pedagogy system and wanted to complete the course with high expectation.

\section{Drop / Change Major Rate per Semester}

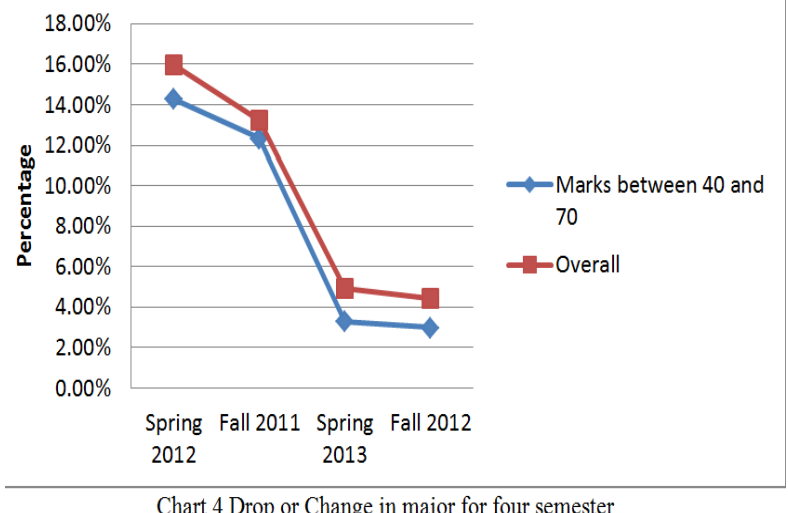

\section{Future Research Plan:}

Study has been started to automate the attendance process and it will control all student activities inside the campus.

i. Attendance through biometric:

The word "biometrics" came from Greek and is divided into two roots: "bio" means life and "metrics" - to measure so it is "life - measure". Any characteristic can serve biometrics if it has the following desirable properties. [17]

1. Commonality - Things which everyone have so that analysis will be possible.

2. Distinctiveness- Items which people have and which is different in everyone

3. Fixedness- That item which is going to collect should not major change over the time

4. Quantifiable. Must be able to measure in less cost
5. Performance- Good speed, accuracy and robustness

6. Appropriateness- Must be suitable and easy to accept by people

7. Circumvention- How easy to fool the system.

8. Security- How safe it is from Hackers to cheat or manipulate original data.

Now a day's cybercrime is growing very fast and hacker are finding new technique to access and modifying any type of data.

Biometrics uses to measure physical characteristics of a person that can store in a database and can be verify. It measures only those that do not change over the time. Like physical characteristic of person never changes, identifyuniquely, easy and inexpensive to record with immediate automated decision. There are several methods for identify and capturing data.

$>\quad$ Retina and Iris scan identification method

$>\quad$ Fingerprint identification method

$>\quad$ Hand geometry and Palm Vein Authentication identification

Face recognition identification

\section{Voice analysis}

$>\quad$ Multimodal recognition method.

Fingerprint and Face recognition scanningbiometrics are easy, cheap and bestthat can provide an ideal solution for school administrators in their effort to identify and track students, provide accurate and auditable student records and provide a safer and more secure environment for students, teachers and staff.

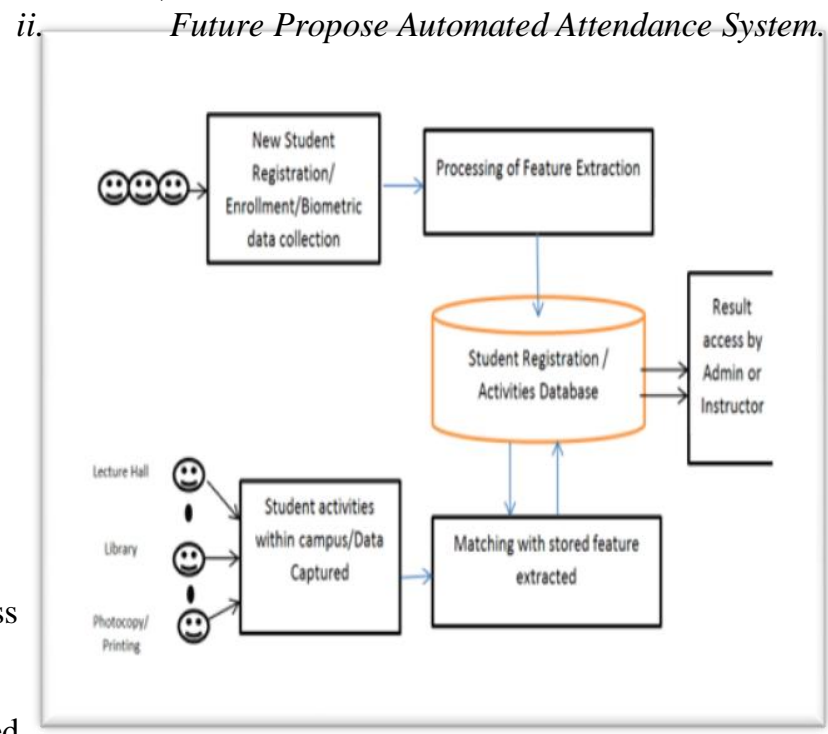

An automated attendance and registration system using biometric has been proposed for the future research to control many activities of the student like Attendance, QU When a new student register in the QU course then their biometric data will be captured and features will extracted and store.

Whenever students do any activity then their data will be collected on the spot and recorded for the generating report and analysis from Admin or Instructor. and time. 
The data can gather from different location within the QU campus and to track student activities.

- Attendance in class room or Lab room

- Accessing QU Library and issuing books and journals.

- Creating pleasant environment inside food court or cafeteria

- Nursing or Medical access can easily monitor and follow up.

- Printer/ photocopier activity can also be control.

- Transport access for correct bus number.

- Special area or Emergency access

- Identification for field trips and outdoor events

Library and Printer/ photocopier access etc.

\section{CONCLUSION}

The study found out that there is no significant difference between Math and Computer in regard to course. The results of this study show a strong, statistically significant correlation between learning event attendance and academic attainment and Performance and retention. It has also found that attendance is a direct determinant of academic performance and attainment. It was noticed that a few students were shown to have an excellent attendance record, yet scored poor results.

Attendance is also the way to motivation the student that ensures that they can easily complete their assignments to improve their skill and prepare for examinations with their full knowledge. Some author says that motivation is an independent feature of student performance but in our result shows that in first year classes and foundation classes their results improve by attendance. Also drop rate is reduced more than 4 to 5 times. Further research to prepare the new model of automatic attendance is required so that university campus will be able to track all the activities of the student.

\section{REFERENCES}

[1] Adelman, C., \& United States. Office of Educational Research and Improvement. (1999). Answers in the tool boxacademic intensity, attendance patterns, and bachelor's degree attainment [microform :]. Washington, DC: U.S. Dept. of Education, Office of Educational Research and Improvement : [Supt. of Docs., U.S. G.P.O., distributor,

[2] Bowen, E., Price, T., Lloyd, S., \& Thomas, S. (2005). Improving the quantity and quality of attendance data to enhance student retention. Journal of Further and Higher Education, 29(4), 375-385. doi: 10.1080/03098770500353714

[3] Chiagozie, O., \& Nwaji, O. (2012). RADIO FREQUENCY IDENTIFICATION (RFID) BASED ATTENDANCE SYSTEM WITH AUTOMATIC DOOR UNIT Academic Research International, 2(2), 168-183.

[4] Cohn, E., \& Johnson, E. (2006). 'Class attendance and performance in principles of economics. Education Economics, 14(2), 211-233. doi: 10.1080/09645290600622954

[5] Colby, J. (2004). Attendance and Attainment - a comparative study. Paper presented at the 5th Annual Conference of the Information and Computer Sciences, University of Ulster.

[6] DeKalb, J. (1999). Student Truancy. ERIC Clearinghouse on Educational Management, ED429334, 125.

[7] Hammen, C. (1994). Attendance and grades in a human physiology course. The American journal of physiology, 287(6)

[8] Johnson, V. (2003). Tracking and monitoring widening participation students: summary guide. Learning and Teaching Support Network (LTSN) Generic Centre.
[9] Kottasz, R. (2005). Reasons for Student Non-Attendance at Lectures and Tutorials: an analysis. Investigations in university teaching and learning, 2(2), 5-16.

[10] Lamdin, D. J. (1996). Evidence of Student Attendance as an Independent Variable in Education Production Functions. The Journal of Educational Research, 89(3), 155-162. doi: 10.1080/00220671.1996.9941321

[11] Moore, R. (2004). Does Improving Developmental Education Students' Understanding of the Importance of Class Attendance Improve Students' Attendance and Academic Performance? Research \& Teaching in Developmental Education, 20(2), 24-39.

[12] Newman- Ford, L., Fitzgibbon, K., Lloyd, S., \& Thomas, s. (2008). A large- scale investigation into the relationship between attendance and attainment: a study using an innovative, electronic attendance monitoring system. Studies in Higher Education, 33(6), 699-717. doi: DOI: 10.1080/03075070802457066

[13] Reid, K. (2008). The causes of non-attendance: An empirical study. Educational Review, 60(4), 345-357 doi: 10.1080/00131910802393381

[14] Roby, D. E. (2003). Research on School Attendance and Student Achievement:

[15] A Study of Ohio Schools. Educational Research Quarterly, 28(1), 3-16.

[16] A.K Jain,R. Bolle and S. Pankanti. " Biometrics. Personal Identification in Network Society".1999 and revised in 2012.

[17] Mohamed Elbashir and Mohammad Shahid Jamil, "Electronic Attendance Monitoring and how attendance rates affect student academic performance in Qatar University, presented at the International Conference for Academic Disciplines in Vienna, Austria, April 2013

\section{BIOGRAPHIES}

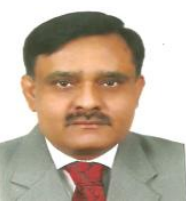

Dr Jamil is currently working as a Research and Planning Coordinator in the Qatar University, Doha, Qatar. He obtained his Ph.D. from VKS University, India. His current researcharea includes e-learning, Knowledge base, Machine learning Algorithms and use of information and communication technology in training and education. $\mathrm{He}$ has awarded two gold medals in Master's degree from Aligarh Muslim University for securing first class first in M.Sc.(Solid State Physics) and M.C.A. (Computer Science). He has published more than 30 research papers in the Internal Journal and Conference.

Dr Mohamed Chabi is an Academic Coordinator in Math Department, Qatar University. He has published several papers in the area of Math and Information Technology. Currently he is doing research in the ELearning area. 